\title{
PENGEMBANGAN SISTEM INFORMASI BEASISWA BERBASIS WEB PADA JURUSAN TEKNIK INFORMATIKA DAN KOMPUTER FT UNM
}

\author{
Sanatang ${ }^{1}$, Massikki $^{2}$ \\ ${ }^{1}$ Pendidikan Teknik Informatika dan Komputer, Universitas Negeri Makassar \\ Sanatang.unm@gmail.com \\ ${ }^{2}$ Pendidikan Teknik Elektro, Universitas Negeri Makassar \\ massikki@unm.ac.id
}

\begin{abstract}
ABSTRAK
Penelitian ini bertujuan untuk menghasilkan pengembangan sistem informasi beasiswa berbasis web pada Jurusan Teknik Informatika dan Komputer Teknik Universitas Negeri Makassar dan untuk mengetahui hasil pengujian sistem informasi beasiswa berbasis web pada Jurusan Teknik Informatika dan Komputer Teknik Universitas Negeri Makassar berdasarkan standar perangkat lunak ISO 25010. Penelitian ini menggunakan model pengembangan prototype. Teknik Pengumpulan data menggunakan wawancara, dokumentasi. dan angket. Pengujian sistem dalam penelitian ini menggunakan standar kualitas perangkat lunak ISO 25010 yang berfokus pada aspek functional suitability, performance efficiency, usability, security dan portability. Hasil pengujian aspek functional suitabilty yang diuji ahli sistem dengan mengisi angket yang berisi 62 pertanyaan berkaitan dengan fungsi-fungsi yang didesain dalam sistem yang dikembangkan, disimpulkan dari aspek functional suitability dapat diterima. Hasil pengujian aspek performance efficiency telah memenuhi waktu load kurang dari 10 detik. Hasil pengujian dari aspek usability menggunakan angket yang diberikan terhadap 103 responden dengan 15 pertanyaan dan diperoleh nilai persentase 88,23\% dengan kategori sangat layak. Hasil pengujian aspek security berada pada tingkat keamanan medium. Hasil pengujian aspek portability dilakukan uji coba pada 6 perangkat dan browser diperoleh nilai berhasil dari semua perangkat.
\end{abstract}

Kata Kunci: Pengembangan, Sistem Informasi, Beasiswa, Berbasis Web

\section{DEVELOPMENT OF WEB-BASED SCHOLARSHIP INFORMATION SYSTEM IN THE DEPARTMENT OF INFORMATICS AND COMPUTER ENGINEERING FT UNM}

\begin{abstract}
ABTRACT
This study aims to produce the development of a web-based scholarship information system at the Department of Informatics and Computer Engineering, Makassar State University and to find out the results of testing a web-based scholarship information system at the Makassar State University Informatics and Computer Engineering Department based on the ISO 25010 software standard. using a prototype development model. Data collection techniques using interviews, documentation. and questionnaire. System testing in this study uses the ISO 25010 software quality standard which focuses on aspects of functional suitability, performance efficiency, usability, security and portability. The results of testing the functional suitability aspect which were tested by system experts by filling out a questionnaire containing 62 questions related to the functions designed in the developed system, concluded from the functional suitability aspect that it was acceptable. The results of the performance efficiency aspect test have met the load time of less than 10 seconds. The test results from the usability aspect using a questionnaire given to 103 respondents with 15 questions and obtained a percentage value of $88.23 \%$ with a very decent category. The results of the security aspect test are at the medium security level. The results of testing the portability aspect were tested on 6 devices and browsers obtained successful scores from all devices.
\end{abstract}

Keyword: Development, Information System, Scholarship, Web Based 


\section{PENDAHULUAN}

Beasiswa merupakan bantuan biaya pendidikan yang diberikan oleh pemerintah, perusahaan dan lembaga kepada mahasiswa kurang mampu atau mahasiswa yang memiliki prestasi dibidang akademik maupun non akademik. Sejalan dengan pendapat Murniasih (2018) menyatakan bahwa "Beasiswa adalah bentuk penghargaan yang diberikan kepada individu agar dapat melanjutkan pendidikan ke jenjang yang lebih tinggi" [1]. Pemberian bantuan biaya pendidikan secara umum bertujuan agar mahasiswa yang kurang mampu dapat mengenyam pendidikan meskipun dengan kondisi ekonomi yang rendah, selain itu beasiswa juga menjadi sebuah penghargaan atas prestasi yang diraih oleh mahasiswa.

Menurut Peraturan Pemerintah Republik Indonesia Nomor 48 tahun 2008 tentang Pendanaan Pendidikan, Bagian kelima, Pasal 27 ayat (1), menyebutkan bahwa Pemerintah dan pemerintah daerah sesuai kewenangannya memberi bantuan biaya pendidikan atau beasiswa kepada peserta didik yang orang tua atau walinya tidak mampu membiayai pendidikannya. Pasal 27 ayat (2), menyebutkan bahwa Pemerintah dan pemerintah daerah sesuai kewenangannya dapat memberi beasiswa kepada peserta didik yang berprestasi [2].

Berdasarkan hasil observasi di Jurusan Teknik Informatika dan Komputer telah diberikan fasilitas jaringan internet namun belum digunakan untuk menyampaikan informasi mengenai beasiswa. Penyebaran informasi beasiswa yang ditawarkan pada Jurusan Teknik Informatika dan Komputer tidak didukung oleh sistem informasi yang dapat mempermudah dalam penyampaian informasi pendaftaran beasiswa dan mempermudah mahasiswa dalam mendapatkan informasi tentang beasiswa. Data penerima beasiswa pada Jurusan Teknik Informatika dan Komputer tidak memiliki database yang membuat mahasiswa penerima bantuan beasiswa dapat melakukan pendaftaran pada bantuan biaya lainnya. Kesulitan ini dikarenakan belum adanya database yang membuat mahasiswa yang menerima beasiswa tidak dapat dideteksi. Hal ini dapat berdampak terhadap tidak meratanya pembagian bantuan biaya dikarenakan mahasiswa yang penerima beasiswa mendapat bantuan lainnya. Berdasarkan pendapat (Sutabri, 2012) Sistem informasi adalah sekelompok sistem didalam forum yang mempertemukan kebutuhan pengolahan transaksi harian yang mendukung fungsi operasi forum yang bersifat manajerial dengan kegiatan strategi dari suatu forum untuk dapat menyediakan fitur yang diperlukan oleh pihak tertentu [3].

Penelitian yang juga telah dilakukan oleh (Ringan Oktiah, 2011) dalam judul "Sistem Informasi Beasiswa Fakultas Teknik Universitas Negeri Yogyakarta" [4]. Tujuan dari penelitian ini adalah merealisasikan rancang sistem informasi sehingga menghasilkan Sistem Informasi Beasiswa yang berkaitan dengan informasi seputar beasiswa yang berada di Universitas Negeri Yogyakarta khususnya pada Fakultas Teknik. Sistem Informasi yang dirancang dapat membantu mahasiswa dalam melakukan pendaftaran beasiswa.

Berdasarkan latar belakang berikut, maka perlu untuk melakukan penelitian pengembangan dengan judul "Pengembangan Sistem Informasi Beasiswa berbasis Web pada Jurusan Teknik Informatika dan Komputer FT UNM".

\section{METODE PENELITIAN}

Jenis penelitian yang digunakan adalah Research and Developmment (R\&D) atau metode penelitian dan pengembangan yang menghasilkan Sistem Informasi Beasiswa berbasis web pada Jurusan Teknik Informatika dan Komputer Fakultas Teknik Universitas Negeri Makassar. Menurut Sugiyono (2019) Metode penelitian dan pengembangan dapat artikan sebagai cara ilmiah untuk meneliti, merancang, memproduksi dan menguji validitas produk yang telah dihasilkan [5].

\section{A. Desain Penelitian}

Model pengembangan yang digunakan dalam penelitian ini adalah model prototype. Sebuah prototype adalah rancangan awal dari sistem perangkat lunak yang digunakan untuk mendemonstrasikan rancangan, uji coba rancangan, dan menemukan lebih banyak masalah dan solusi yang memungkinkan terjadi [ 6].

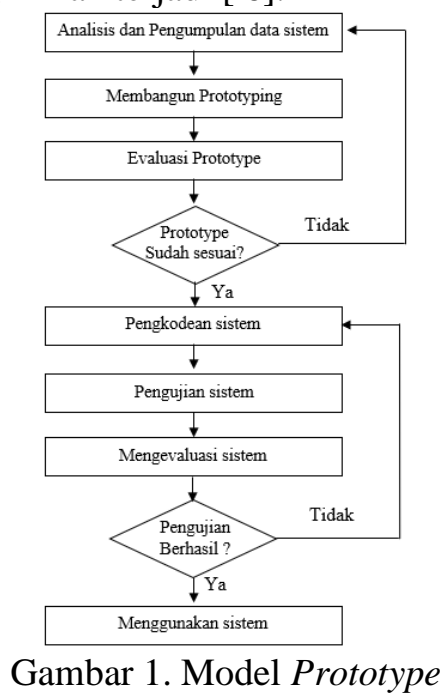




\section{B. Instrumen dan Pengumpulan Data}

Pengujian dilakukan dengan menggunakan standar ISO 25010 memiliki delapan karakteristik [7]. Pada penelitian ini digunakan White Box Testing dan 5 karakteristik pengujian yang ada pada ISO 25010, yaitu aspek functional suitability, performance efficiency, usability, Security dan portability.

Tahap Pengujian functional suitability dengan menggunakan angket yang berisi pertanyaan mengenai fungsi yang dimiliki sistem dengan metode penilaian ahli. Tahap pengujian performance efficiency dengan menggunakan bantuan aplikasi GTMatrix dalam menghitung skor rata-rata semua halaman dan waktu respon yang diuji. Tahap pengujian usability dilakukan dengan menggunakan angket yang diberikan kepada pengguna. Tahap pengujian security dengan menggunakan aplikasi Acunetix Web Vulnerability Scanner yang mengukur tingkat keamanan dari sistem yang dikembangkan.dan pengujian portability dengan melakukan uji coba terhadap sistem baik pada desktop maupun mobile.

\section{Teknik Analisis Data}

Data yang diterima dari penilai ahli kemudain akan dihitung dengan menggunakan rumus :

$\mathrm{YA}=\left(\sum\right.$ Skor/item pertanyaan $) \times 100 \%$

Setelah mendapatkan persentase kelayakan maka dapat ditarik kesimpulan pengujian performance efficiency menjadi data kualitatif dengan menggunakan Tabel konversi:

TABEL 1. KONVERSI KUALITATIF

\begin{tabular}{cc}
\hline Presentase Kelayakan & Kriteria \\
\hline$\geq 50 \%$ & Dapat Diterima \\
$<50 \%$ & Ditolak \\
\hline
\end{tabular}

Aplikasi GTMatriks akan menampilkan hasil pengujian performance efficiency. Pengujian Usability dengan mengumpulkan data dilakukan analisis menggunakan teknik analisis deskriptif kualitatif. Analisis kelayakan aplikasi menggunakan rumus berikut [5].

$$
\text { Presentase kelayakan }=\frac{\text { Skor } \text { perolehan }}{\text { Skor } \text { maksimal }}
$$

Hasil dari presentase skor kemudian dibandingkan dengan tabel koneversi kualitatif dari presentase kelayakan sebagai berikut :

TABEL 2. KONVERENSI SKALA LIKERT

\begin{tabular}{ccc}
\hline No & Presentase $(\%)$ & Katagori \\
\hline 1 & $81 \%-100 \%$ & Sangat Layak \\
2 & $61 \%-80 \%$ & Layak \\
3 & $41 \%-60 \%$ & Cukup Layak \\
4 & $21 \%-40 \%$ & Tidak Layak \\
5 & $<21 \%$ & Sangat Tidak Layak \\
\hline
\end{tabular}

Hasil pengujian security sistem dengan menggunakan aplikasi Acunetix Web Vulnerability Scanner yang mengukur tingkat keamanan dari sistem yang dikembangkan. Pengujian portability dilakukan dengan secara manual menjalankan sistem informasi yang dikembangkan diberbagai macam browser baik dari versi desktop dan mobile.

\section{Lokasi dan Subjek Penelitian}

Penelitian ini dilaksanakan di kampus Universitas Negeri Makassar khususnya di Jurusan Teknik Informatika dan Komputer Fakultas Teknik Universitas Negeri Makassar dengan subjek penelitian yaitu civitas akademik Jurusan Teknik Informatika dan Komputer.

\section{HASIL DAN PEMBAHASAN}

Hasil penelitian ini merupakan sistem informasi beasiswa berbasis web pada jurusan teknik informatika dan komputer fakultas teknik universitas negeri makassar. Sistem yang dibuat dengan menggunakan html, php, css dan javascript dengan menggunakan software visual studio code dan framework codeigniter. Pengembangan sistem informasi beasiswa berbasis web pada jurusan Teknik informatika dan komputer fakultas teknik universitas negeri makassar bertujuan untuk memudahkan dalam pengurusan beasiswa.

\section{A. Analisis dan Pengumpulan Data Sistem}

Tahap analisis pada sistem informasi beasiswa dilakukan dengan menganalisis dan mengumpulkan informasi berkaitan dengan sistem dengan melakukan observasi langsung dan wawancara di Jurusan Teknik Informatika dan Komputer. Hasil dari tahapan ini diperoleh data kebutuhan sistem seperti berikut:

1. Ketua Jurusan Teknik Informatika dan Komputer menilai bahwa sistem informasi Beasiswa sangat dibutuhkan dalam membantu proses pengolahan informasi mengenai beasiswa.

2. Ketua Jurusan Teknik Informatika dan Komputer menilai bahwa pemanfaatan teknologi informasi dalam pengelolaan informasi beasiswa dapat memudahkan, cepat, dan meminimalisir mahasiswa yang melakukan pendaftaran beasiswa lebih dari satu beasiswa.

3. Level akses (user) terdiri dari admin, tim seleksi, dan mahasiswa.

4. Data yang dilakukan user untuk mengakses sistem informasi berupa username dan password.

5. Admin dapat menambah, mengedit, menghapus, mencari dan mencetak data hasil seleksi.

6. Tim seleksi dapat melakukan seleksi berkas terhadap berkas pendaftar beasiswa yang akan diterima maupun ditolak.

7. Mahasiswa dapat melakukan pengajuan 
beasiswa, mengunggah berkas pendaftaran serta melihat status pendaftaran yang diajukan.

\section{B. Membangun Prototyping}

Berdasarkan hasil dari analisis dan pengumpulan data awal dilanjutkan dengan tahap membangun prototyping yang membuat rancangan sementara yang menjadi gambaran umum terhadap user tentang sistem informasi yang dibangun.

\section{Evaluasi Prototype}

Tahap evaluasi prototype merupakan tahap setelah membuat prototype yang dilakukan oleh admin untuk mengetahui apakah prototype yang dibuat sesuai dengan kebutuhan pengguna atau belum. Jika prototype telah sesuai maka melanjutkan ke tahap pengkodean sistem, jika belum sesuai maka diulang dari langkah 1, langkah 2 dan langkah 3.

\section{Pengkodean Sistem}

Tahap pengkodean sistem merupakan realisasi dari prototype yang telah disepakati dan diterjemahkan kedalam bahasa pemrograman. Bahasa pemrograman yang digunakan adalah html, php css dan javascript. Berikut merupakan hasil dari realisasi rancangan antarmuka sistem yang dikembangkan:

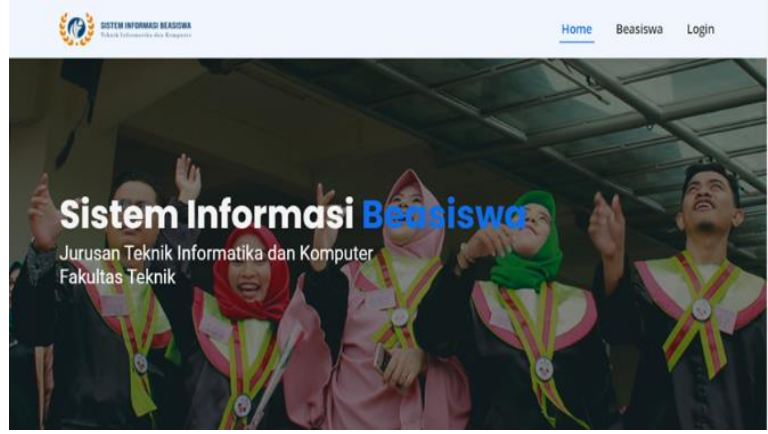

Gambar 2. Tampilan Utama

Halaman utama merupakan halaman yang diakses pertama kali ketika masuk kedalam sistem, terdapat informasi mengenai beasiswa yang berada di Jurusan Teknik Informatika dan Komputer.

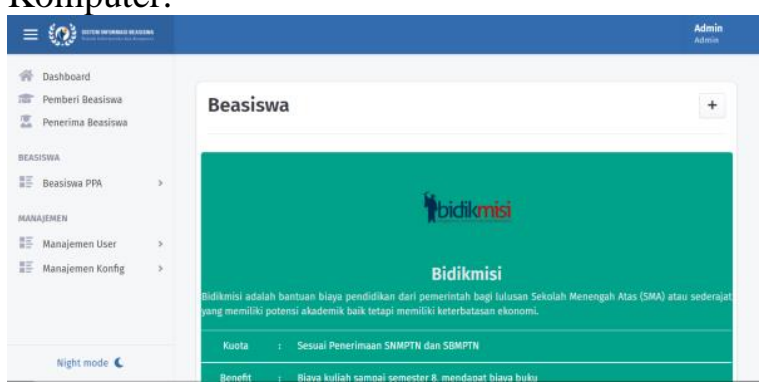

Gambar 3. Tampilan User (Admin)
Halaman Admin terdapat menu dashboard, pemberi beasiswa, penerima beasiswa, beasiswa PPA, manajemen user dan manajemen konfig. Menu dashboard merupakan halaman utama admin. Menu pemberi beasiswa merupakan halaman untuk memanajemen data beasiswa. Menu penerima beasiswa merupakan halaman untuk memanajemen data mahasiswa yang menerima beasiswa. Menu PPA merupakan menu untuk memanajemen pendaftaran beasiswa PPA. Menu manajemen user merupakan halaman untuk melakukan manajemen user dan menu manajemen konfig merupakan halaman untuk melakukan manajemen pembukaan beasiswa PPA.

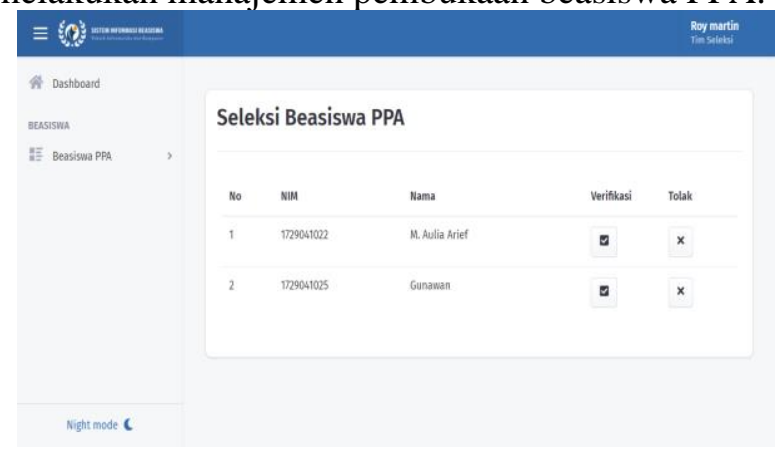

Gambar 4. Tampilan User (Tim Seleksi)

Halaman Tim Seleksi terdapat menu dashboard dan menu seleksi beasiswa PPA. Menu dashboard merupakan halaman utama Tim Seleksi. Menu Seleksi PPA merupakan menu untuk menyeleksi pendaftaran beasiswa PPA.

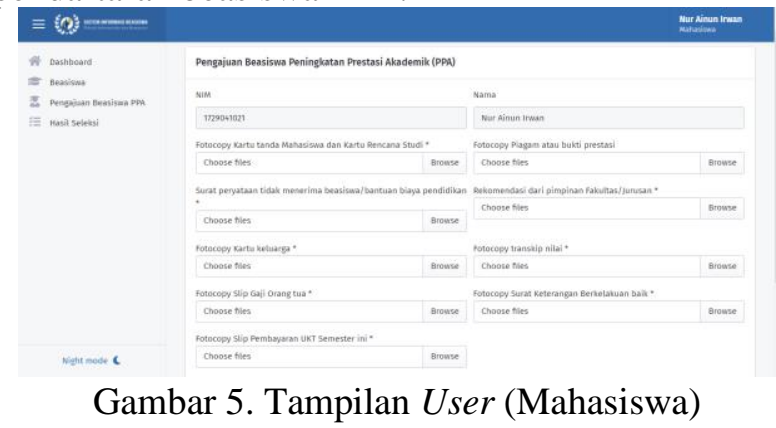

Halaman Mahasiswa terdapat menu dashboard dan menu pendaftaran beasiswa PPA. Menu dashboard merupakan halaman utama mahasiswa. Menu pendaftaran PPA merupakan menu untuk menlakukan pendaftaran beasiswa PPA.

\section{E. Pengujian Sistem}

\section{Pengujian Functional Suitability}

Pengujian Funtional Suitability menggunakan (1) maka diperoleh hasil persentase $>50 \%$ dari pengujian functional suitability. Hasil tersebut dikonversi ke data kualitatif dan berdasarkan skala penilaian dari skor presentasi, maka didapat kualitas sistem dari aspek functional suitability dapat diterima. 


\section{Pengujian Performance Efficiency}

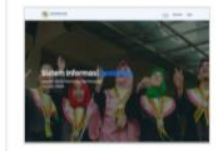
Latest Performance Report for: hitps://sib-fik.com/

Report generected: Weo, Sep 22.2021 12.57 MM-0700


using 6
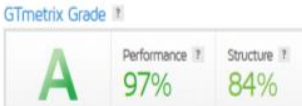
Web Vitals $:$ L.eP : Oms 0.05

Gambar 6. Pengujian Performance Efficiency

Data dari pengujian performance efficiency menggunakan aplikasi GTMatrix diperoleh sebesar 97\%, struktur sebesar $84 \%$, waktu load sebesar 1,1 sekon dengan predikat performance A. Berdasarkan hasil pengujian performance efficiency menggunakan GTMatriks telah memenuhi waktu load kurang dari 10 detik.

\section{Pengujian Security}

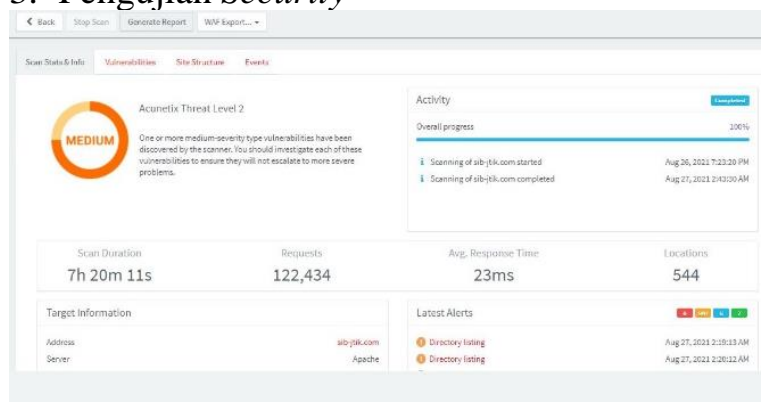

Gambar 7. Hasil Pengujian Security

Pengujian Security menunjukan Sistem Informasi Beasiswa memiliki tingkat keamanan level 2. Aplikasi Acunetix Web Vulnerability Scanner mengidentifikasi bahwa adanya kesalahan pada konfigurasi server maupun kekurangan pengkodean pada web.

\section{Pengujian Portability}

Pengujian aspek portability dilakukan dengan cara menggunakan berbagai web browser yang berbeda untuk menjalankan Sistem Informasi. Pengujian dilakukan dengan menggunakan enam jenis browser pada tiga jenis sistem operasi yang berbeda. Hasil pengujian menunjukan sistem dapat dioperasikan diberbagai browser baik di mobile dan desktop.

\section{F. Evaluasi Sistem}

Tahap evaluasi sistem merupakan uji coba kepada pengguna sistem informasi beasiswa pada jurusan teknik informatika dan komputer fakultas teknik universitas negeri makassar pada user sistem informasi khususnya tim seleksi beasiswa dan mahasiswa di jurusan teknik informatika dan komputer fakultas teknik universitas negeri makassar. Hal ini dilakukan karena sistem informasi beasiswa akan di terapkan jurusan teknik informatika dan komputer fakultas teknik universitas negeri makassar. Pengujian usability dilakukan dengan memberikan angket terhadap 103 responden dilingkup Jurusan Teknik Informatika dan Komputer Fakultas Teknik Universitas Negeri Makassar. Pengujian usability bertujuan untuk melihat sejauh mana pengguna sistem dapat berinteraksi secara efektif dan melihat tingkat kepuasan pengguna dalam menggunakan sistem informasi.

TABEL 3. HASIL PENGUJIAN USABILITY

\begin{tabular}{l|l|l|l}
\hline Skor Total & Skor Maksimal & Presentase & Kategori \\
\hline 66,17 & 75 & $88,23 \%$ & $\begin{array}{l}\text { Sangat } \\
\text { Layak }\end{array}$ \\
\hline
\end{tabular}

Berdasarkan data pada tabel menampilkan data hasil tanggapan dari responden yang telah mencoba sistem informasi ini. Rangkuman penilaian dapat diperoleh nilai persentase 88,23\% dengan kategori Sangat Layak dalam pengujian usability.

\section{SIMPULAN}

1. Berdasarkan hasil penelitian, dihasilkan sistem informasi beasiswa berbasis web pada Jurusan Teknik Informatika dan Komputer Teknik Universitas Negeri Makassar dibuat dengan model pengembangan prototype, CodeIgniter 3 sebagai framework, dibangun menggunakan bahasa pemrograman $P H P$ dan $H T M L$ dengan $M y S q l$ sebagai databasenya.

2. Berdasarkan hasil penelitian menggunakan standar pengujian perangkat lunak ISO 25010, pada aspek pengujian functional suitability dengan kategori dapat diterima, aspek pengujian performance efficiency telah memenuhi waktu load kurang dari 10 detik, aspek pengujian usability dengan jumlah responden 103 diperoleh nilai persentase 88,23\% dengan kategori sangat layak, aspek pengujian security dengan kategori medium dan aspek pengujian portability dapat diakses dengan baik menggunakan desktop maupun mobile

\section{DAFTAR PUSTAKA}

[1] D. P. Sari, "Penerapan Metode Saw (Simple Additive Weighting) dalam Sistem Pendukung Keputusan untuk Menentukan Penerima Beasiswa pada Smk N 2 Payakumbuh," vol. 5, no. 2, p. 10.

[2] Republik Indonesia, Peraturan pemerintahRrepublik Indonesia nomor 48 Tahun 2008 tentang pendanaan pendidikan. Jakarta, 2008.

[3] T. Sutabri, Analisis sistem informasi. Yogyakarta: CV Andi Offset, 2012.

[4] R. Oktiah, "Sistem informasi beasiswa Fakultas Teknik Universitas Negeri Yogyakarta," 
Yogyakarta, 2011.

[5] Sugiyono, Metodologi penelitian dan pengembangan Research and development. Bandung: Alfabeta, 2019.

[6] W. Nugraha and M. Syarif, "Penerapan metode Prototype dalam perancangan sistem informasi penghitungan volume dan cost penjualan minuman berbasis website," jusim, vol. 3, no. 2, pp. 94-101, Dec. 2018, doi: 10.32767/jusim.v3i2.331.

[7] H. Gunawan and A. Triantoro, "[No title found]," JUTEI, vol. 1, no. 1, Apr. 2017, doi: 10.21460/jutei.2017.11.6.

[8] T. N. Sari, "Analisis kualitas dan pengembangan sistem informasi akademik berbasis web menggunakan standard iso 9126," JIKO (Jurnal Informatika dan Komputer), vol. 1, no. 1, 2016. 